Received July 19, 2017

Revised 1st, September 12, 2017 2nd, October 16, 2017 Accepted November 22, 2017

\section{Corresponding author}

Ju Deok Kim, M.D., Ph.D. Department of Anesthesiology and Pain Medicine, Kosin University College of Medicine, 262 Gamcheon-ro, Seo-gu, Busan 49267, Korea

Tel: 82-51-990-6283

Fax: 82-51-254-2504

E-mail: uamyfriends@hanmail.net ORCID

http://orcid.org/0000-0002-9236-5183

\title{
The effects of loading dose administration rate of dexmedetomidine on sedation and dexmedetomidine requirement in elderly patients undergoing spinal anesthesia
}

\author{
Hsi Chiang Kung, Chia Chi Cheng, Dong Hee Kang, \\ Hyung Joo Jeong, Yu Som Shin, Doo Sik Kim, Sie Jeong Ryu, \\ Kyung Han Kim, and Ju Deok Kim
}

Department of Anesthesiology and Pain Medicine, Kosin University College of Medicine, Busan, Korea

Background: This study evaluated the effect of decrease in loading dose administration rate of dexmedetomidine (DMT) on sedation and DMT requirement in elderly patients.

Methods: Fifty-eight patients over 65 years old with ASA I-II who were planned to receive DMT sedation during spinal anesthesia were randomly assigned to two groups. Group $S(n=29)$ received a $0.5 \mu g / k g$ DMT loading dose over 20 minutes, while group $C(n=29)$ received the DMT loading dose over 10 minutes. Then, both groups received a continuous infusion of $0.4 \mu \mathrm{g} / \mathrm{kg} / \mathrm{h}$. The sedative status was recorded before and at $5,10,15,20,25$, and 30 minutes after administration of DMT and at the end of the anesthesia according to the Ramsay sedation scale (RSS). Also, the time to reach RSS3 (patients asleep, responsive to commands) and the dose of DMT until reaching RSS-3 were recorded.

Results: The time to reach RSS-3 was similar between the two groups (group $S=16.0 \pm$ 4.3 minutes vs. group $C=15.5 \pm 4.2$ minutes, $P=0.673$ ). However, the DMT required to reach RSS-3 in group $S$ was significantly lower than that in group $C(23.3 \pm 7.1$ vs. $32.5 \pm 6.0 \mu \mathrm{g}, \mathrm{P}<0.001$ ). There was no difference in RSS between the two groups from the administration of DMT to the end of the anesthesia $(P=0.927)$.

Conclusions: Decreasing the administration rate of the DMT loading dose did not delay the onset of RSS-3 sedation and reduced the DMT requirement in elderly patients.

Key Words: Adrenergic alpha-2 receptor agonists, Aged, Dexmedetomidine, Hypnotics and sedatives, Spinal anesthesia.

\section{INTRODUCTION}

Dexmedetomidine (DMT) is a selective $\alpha-2$ agonist that has both sedative and analgesic effects [1-3]. It is clinically widely used because it induces mild respiratory depression in patients who are responsive to mild tactile stimulation during sedation [4-6]. Therefore, DMT is an effective sedative to reduce anxiety in patients undergoing regional anesthesia.

The recommended dose of DMT includes a loading dose of $1 \mu \mathrm{g} / \mathrm{kg}$ over 10 minutes, followed by a continuous infusion of $0.2-0.7 \mu \mathrm{g} / \mathrm{kg} / \mathrm{h}$ [7]. In addition to its sedative properties, DMT can also reduce heart rate (HR), cardiac output, and circulating catecholamine in a dose-dependent fashion. [7-9]. The use of DMT in elderly patients is associated with a

This is an Open Access article distributed under the terms of the Creative Commons Attribution Non-Commercial License (http://creativecommons.org/licenses/by-nc/4.0) which permits unrestricted non-commercial use, distribution, and reproduction in any medium, provided the original work is properly cited. 
higher incidence of side effects, including severe hypotension and bradycardia, than in young adults [10]. Thus, it is recommended to use a reduced loading dose of DMT in elderly patients [7].

The sedative and hemodynamic effects of DMT can vary by dose and method of administration. Therefore, several studies have assessed different loading doses or various maintenance doses of DMT following the same loading dose in elderly patients in order to avoid adverse events while maintaining adequate sedation $[11,12]$. However, there has been no report on the effects of DMT on sedation and hemodynamics when changing the administration duration of the same load dose.

Therefore, the purpose of this study was to determine the appropriate administration method of DMT loading dose in the elderly. We compared the effects of sedation and hemodynamics using different loading dose administration durations (of $0.5 \mu \mathrm{g} / \mathrm{kg}$ DMT) in the elderly. We also investigated the side effects, including desaturation.

\section{MATERIALS AND METHODS}

Written informed consent was obtained from patients and approved by the Institutional Ethics Committee of the Kosin University Gospel Hospital (KUGH 2016-10-019). The study included patients over 65 years old who were planned to undergo elective orthopedic surgery under spinal anesthesia. All of the included patients had American Society of Anesthesiologists physical status classification I or II. Patients were excluded if they had a past history of head or neck surgery; severe renal, liver, or cardiac disease; or mental disease. Obese patients (body mass index $>30 \mathrm{~kg} / \mathrm{m}^{2}$ ) were also excluded.

A total of 58 patients were included as subjects. Patients were randomly divided into two groups using computer-generated random numbers. Those in group $S(n=29)$ received a DMT loading dose of $0.5 \mu \mathrm{g} / \mathrm{kg}$ over 20 minutes, followed by a continuous infusion of $0.4 \mu \mathrm{g} / \mathrm{kg} / \mathrm{h}$. In contrast, those in group C $(\mathrm{n}=29)$ received the loading dose of $0.5 \mu \mathrm{g} / \mathrm{kg}$ DMT over 10 minutes, followed by a continuous infusion of $0.4 \mu \mathrm{g} /$ $\mathrm{kg} / \mathrm{h}$. In both groups, DMT was administered for up to 10 minutes before the end of anesthesia.

None of the patients received premedication. After entering the operating room, routine monitoring was used, including non-invasive blood pressure measurement, pulse oximetry, and electrocardiography. Two anesthesiologists and a nurse from the anesthesiology department attended the anesthesia. The nurse prepared the study drug and controlled the administration rate of DMT loading dose according to patient group. Therefore, both anesthesiologists were blinded to the patient assignment. All spinal anesthesia procedures and anesthetic management were performed by an experienced anesthesiologist with exception of control over the administration rate. The other anesthesiologist recorded all measured data.

Prior to beginning the spinal anesthesia, $300 \mathrm{ml}$ of lactated Ringer's solution was administrated over a 5-minutes in order to maintain the intravascular volume. For spinal anesthesia, the patient was positioned in the lateral decubitus position. The L3-4 inter vertebral space was estimated based on the superior iliac crest. After confirmation of free-flowing, clear cerebrospinal fluid using the midline approach with a $25 \mathrm{G}$ spinal needle, 8-11 mg of heavy bupivacaine was administered depending on the height and weight of the patient. The patient was then positioned in the supine position, and DMT was started according to the patient group. DMT (Precedex ${ }^{\circledR}$, Hospira, USA, $200 \mu \mathrm{g} / 1 \mathrm{ml}$ ) was diluted in $49 \mathrm{ml}$ normal saline for a total of $50 \mathrm{ml}$ of solution. The level of the sensory block was confirmed using the pin-prick test. Patients were excluded if they had incomplete spinal anesthesia, confirmed anesthesia over the sixth thoracic vertebrae, or required three or more vasopressors to maintain a systolic blood pressure $>90 \mathrm{mmHg}$. The sedative status was recorded using the Ramsay sedation scale (RSS) before DMT was administered; at 10, $15,20,25$, and 30 minutes after it was given; and at the end of anesthesia [13]. The time to reach RSS-3 (in which patients are asleep but responsive to commands) was measured. The sedative status was confirmed every minute after initiating DMT. Also, the dose of DMT administered until RSS-3 sedation was recorded. Mean arterial blood pressure (MAP), HR were recorded before DMT administration; immediately after; at 10, 20, 30 minutes after administration of DMT; and at the end of the anesthesia. The incidence of hypotension (systolic blood pressure $<90 \mathrm{mmHg}$ ), bradycardia ( $\mathrm{HR}<45$ beats/min), and desaturation (peripheral oxygen saturation measured by pulse oximetry $\left.\left[\mathrm{SpO}_{2}\right]<90 \%\right)$ were also recorded. If a patient developed hypotension, $5 \mathrm{mg}$ of ephedrine was given with a $200 \mathrm{ml}$ of lactated Ringer's solution over 5 minutes. In the case of bradycardia, $0.5 \mathrm{mg}$ of atropine was 
given intravenously. If a patient developed oxygen desaturation, the head was turned to the side to induce spontaneous breathing. Oxygen was administered by facial mask if the desaturation persisted despite this position change.

Deterministic simulations were performed using Asan Pump ver. 2.1.3 software (Bionet Co. Ltd., Korea; http://www. fit4nm.org/download, last accessed: June 24, 2014). The time courses of plasma DMT concentrations after a loading dose of $0.5 \mu \mathrm{g} / \mathrm{kg}$ over 10 or 20 minutes, and after zero-order infusion at the rate of $0.4 \mu \mathrm{g} / \mathrm{kg} / \mathrm{h}$ for 50 or 40 minutes, were simulated in a hypothetical patient weighing $60 \mathrm{~kg}$. The pharmacokinetic parameters used in the simulations were obtained from previous studies $[14,15]$.

In a pilot studies in elderly patients, the mean time to induce RSS-3 was 15 minutes (with a standard deviation of 4 minutes) using a DMT loading dose of $0.5 \mu \mathrm{g} / \mathrm{kg}$ over $10 \mathrm{~min}$ utes and followed by a continuous administration of $0.4 \mu \mathrm{g} /$ $\mathrm{kg} / \mathrm{h}$. Therefore, we hypothesized that there would be a $>25 \%$ difference in time to reach RSS-3 sedation when loading dose was administrated over 20 minutes. Twenty-nine patients in each group were needed for a power analysis of 0.8 ( $\alpha=0.05$, $\beta=0.2$ ).

All statistical analysis was performed using IBM SPSS Statistics 24.0 software (IBM Co., USA). The KolmogorovSmirnov test was used to test the normal distribution of continuous data. We compared normally distributed data between the two groups using two-tailed unpaired and Student's $t$-tests. Normally distributed data are shown as mean and standard deviation. Normally distributed data are shown as mean and standard deviation. Non-normally distributed data were compared as median value using the MannWhitney $U$ test. Categorical data, including the incidence of complications, were compared using the chi-square test or Fisher's exact test. Changes in RSS, MAP, and HR over time within and between groups were measured using repeatedmeasures analysis of variance and adjusted for multiple comparisons using the Bonferroni method. P values $<0.05$ were considered statistically significant.

\section{RESULTS}

All patients completed the study. There were no significant

Table 1. Demographic Data and Level of Sensory Block

\begin{tabular}{lccc}
\hline \multicolumn{1}{c}{ Variable } & $\begin{array}{c}\text { Group } \\
(\mathrm{n}=29)\end{array}$ & $\begin{array}{c}\text { Group C } \\
(\mathrm{n}=29)\end{array}$ & P value \\
\hline Age $(\mathrm{yr})$ & $69.7 \pm 4.6$ & $71.2 \pm 6.9$ & 0.338 \\
Sex $(\mathrm{M} / \mathrm{F})$ & $14 / 15$ & $12 / 17$ & 0.257 \\
Weight $(\mathrm{kg})$ & $61.3 \pm 10.3$ & $58.6 \pm 7.4$ & 0.601 \\
Body mass index $\left(\mathrm{kg} / \mathrm{m}^{2}\right)$ & $24.4 \pm 3.1$ & $23.3 \pm 2.4$ & 0.224 \\
Level of sensory block & $9.8 \pm 1.2$ & $9.6 \pm 1.2$ & 0.647 \\
\hline
\end{tabular}

Values are presented as mean \pm SD or number of patients. Group S: a loading dose of dexmedetomidine (DMT) of $0.5 \mu \mathrm{g} / \mathrm{kg}$ over 20 minutes, followed by a continuous infusion of $0.4 \mu \mathrm{g} / \mathrm{kg} / \mathrm{h}$. Group C: a loading dose of DMT of $0.5 \mu \mathrm{g} / \mathrm{kg}$ over 10 minutes, followed by a continuous infusion of $0.4 \mu \mathrm{g} / \mathrm{kg} / \mathrm{h}$. Levels of sensory block are presented as 9th thoracic vertebra $=9,10$ th thoracic vertebra $=10$, 1st lumbar vertebra $=13$.
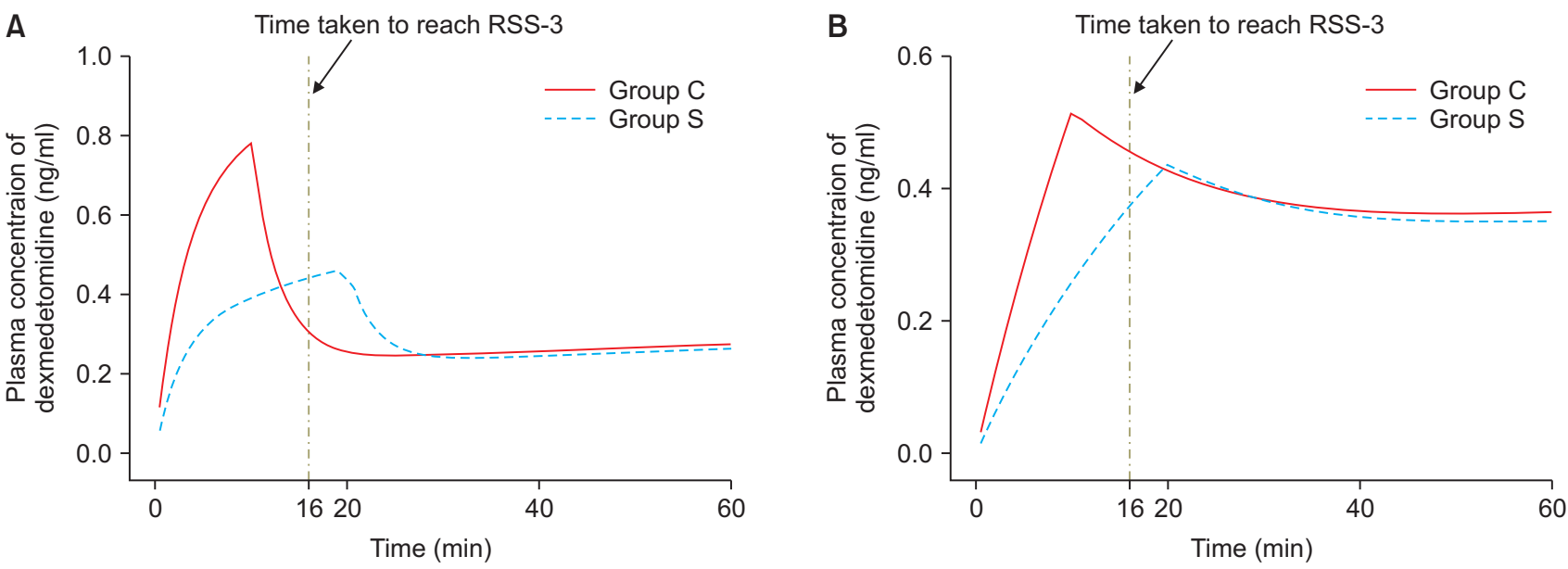

Fig. 1. Simulated time courses of plasma dexmedetomidine concentrations after a loading dose of $0.5 \mu \mathrm{g} / \mathrm{kg}$ over 10 or 20 minutes, and after zeroorder infusion at the rate of $0.4 \mu \mathrm{g} / \mathrm{kg} / \mathrm{h}$ for 50 or 40 minutes in a hypothetical patient weighing $60 \mathrm{~kg}$. The pharmacokinetic parameters used in the simulations were obtained from results of lirola et al. [14] and Angst et al. [15]. RSS: Ramsey sedation scale. 
differences in demographic data or level of spinal anesthesia between the two groups (Table 1).

The simulated plasma concentration of group $\mathrm{C}$ was higher than group S until reaching RSS-3 (Fig. 1). After reaching RSS-3, a similar sedation status was obtained until the end of anesthesia in both groups.

The time required to reach RSS-3 was similar between the two groups (group $\mathrm{S}=16.0 \pm 4.3$ minutes vs. group $\mathrm{C}=15.5$ \pm 4.2 minutes, $\mathrm{P}=0.673$ ). However, the $\mathrm{DMT}$ requirement to reach RSS-3 in group S was significantly lower than that in group C (23.3 $\pm 7.1 \mu$ g vs. $32.5 \pm 6.0 \mu \mathrm{g}, \mathrm{P}<0.001)($ Table 2$)$.

Table 2. Sedation and Duration of Dexmedetomidine Administration

\begin{tabular}{lccr}
\hline \multicolumn{1}{c}{ Variable } & $\begin{array}{c}\text { Group S } \\
(\mathrm{n}=29)\end{array}$ & $\begin{array}{c}\text { Group C } \\
(\mathrm{n}=29)\end{array}$ & P value \\
\hline Duration of anesthesia $(\mathrm{min})$ & $110.3 \pm 34.7$ & $116.6 \pm 43.1$ & 0.548 \\
Time to reach RSS-3 (min) & $16.0 \pm 4.3$ & $15.5 \pm 4.2$ & 0.673 \\
$\begin{array}{l}\text { Dose of DMT until reaching } \\
\text { RSS-3 }(\mu \mathrm{g})\end{array}$ & $23.3 \pm 7.1$ & $32.5 \pm 6.0$ & $<0.001$ \\
$\begin{array}{l}\text { Total dexmedetomidine dose } \\
(\mu \mathrm{g})\end{array}$ & $56.7 \pm 16.0$ & $63.9 \pm 17.5$ & 0.112 \\
\hline
\end{tabular}

Values are presented as mean \pm SD. Group S: a loading dose of dexmedetomidine (DMT) of $0.5 \mu \mathrm{g} / \mathrm{kg}$ over 20 minutes, followed by a continuous infusion of $0.4 \mu \mathrm{g} / \mathrm{kg} / \mathrm{h}$. Group C: a loading dose of DMT of 0.5 $\mu \mathrm{g} / \mathrm{kg}$ over 10 minutes, followed by a continuous infusion of $0.4 \mu \mathrm{g} /$ $\mathrm{kg} / \mathrm{h}$. RSS: Ramsey sedation scale.

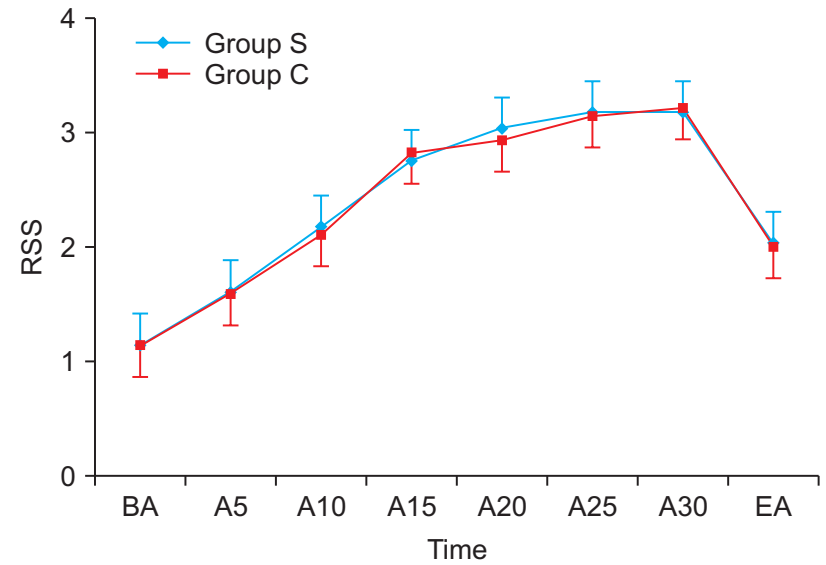

Fig. 2. Changes in Ramsey sedation scale (RSS). Graph shows the mean values and standard deviations. Group S: a loading dose of dexmedetomidine (DMT) of $0.5 \mu \mathrm{g} / \mathrm{kg}$ over 20 minutes, followed by a continuous infusion of $0.4 \mu \mathrm{g} / \mathrm{kg} / \mathrm{h}$. Group C: a loading dose of DMT of $0.5 \mu \mathrm{g} / \mathrm{kg}$ over 10 minutes, followed by a continuous infusion of 0.4 $\mu \mathrm{g} / \mathrm{kg} / \mathrm{h}$. There was no significant difference between the two groups $(P=0.927)$. BA: before administration of DMT, A5, A10, A15, A20, A25, A30: 5, 10, 15, 20, 25 and 30 minutes after administration of DMT, EA: end of anesthesia.
There were no significant difference in RSS between the two groups from the time of DMT administration through the end of anesthesia (Fig. 2).

There was no significant difference in incidence of desaturation between the two groups, with 2 cases in group $S$ and 4 cases in group C. Oxygen therapy was not required in any of the cases. There were 2 cases of bradycardia in each group. There were 5 cases in group $\mathrm{S}$ and 9 in group $\mathrm{C}$ in which fluid and ephedrine administration were required given decreases in MAP after DMT administration; there was no significant difference between the two groups (Table 3).

Table 3. Distribution of Side Effects of Two Groups

\begin{tabular}{lll}
\hline \multicolumn{1}{c}{ Variable } & $\begin{array}{l}\text { Group S } \\
(\mathrm{n}=29)\end{array}$ & \multicolumn{1}{c}{$\begin{array}{l}\text { Group C } \\
(\mathrm{n}=29)\end{array}$} \\
\hline Hypotension $(\mathrm{SBP}<90 \mathrm{mmHg})$ & $5(17.2)$ & $9(31.0)$ \\
Bradycardia $(\mathrm{HR}<45$ beats $/ \mathrm{min})$ & $2(6.9)$ & $2(6.9)$ \\
Desaturation $\left(\mathrm{SpO}_{2}<90 \%\right)$ & $2(6.9)$ & $4(13.8)$
\end{tabular}

Values are presented as number (\%). Group S: a loading dose of dexmedetomidine (DMT) of $0.5 \mu \mathrm{g} / \mathrm{kg}$ over 20 minutes, followed by a continuous infusion of $0.4 \mu \mathrm{g} / \mathrm{kg} / \mathrm{h}$. Group C: a loading dose of DMT of 0.5 $\mu \mathrm{g} / \mathrm{kg}$ over 10 minutes, followed by a continuous infusion of $0.4 \mu \mathrm{g} /$ $\mathrm{kg} / \mathrm{h}$. SBP: systolic blood pressure, $\mathrm{HR}$ : heart rate, $\mathrm{SpO}_{2}$ : peripheral oxygen saturation measured by pulse oximetry. There was no significant difference in side effects between the two groups.

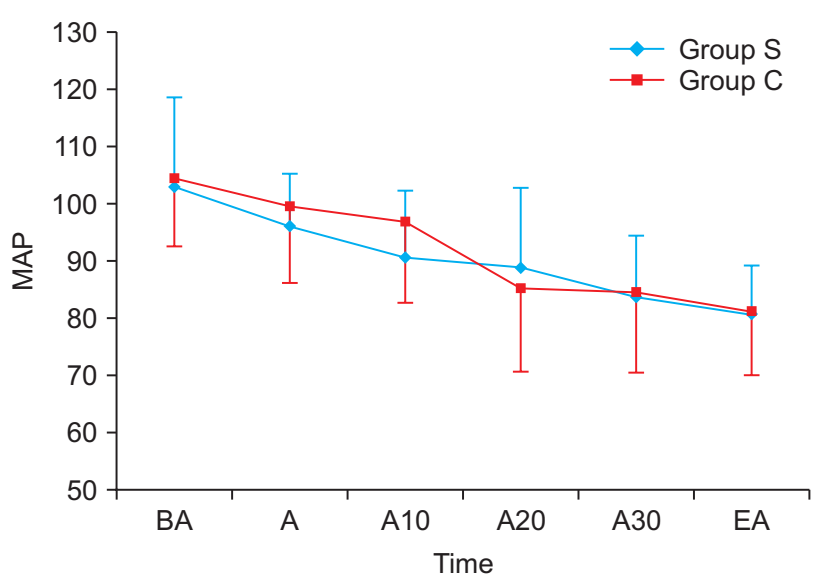

Fig. 3. Changes in mean arterial pressure (MAP). Graph shows the mean values and standard deviations. Group S: a loading dose of dexmedetomidine (DMT) of $0.5 \mu \mathrm{g} / \mathrm{kg}$ over 20 minutes, followed by a continuous infusion of $0.4 \mu \mathrm{g} / \mathrm{kg} / \mathrm{h}$. Group C: a loading dose of DMT of 0.5 $\mu \mathrm{g} / \mathrm{kg}$ over 10 minutes, followed by a continuous infusion of $0.4 \mu \mathrm{g} /$ $\mathrm{kg} / \mathrm{h}$. A significant effect of time $(P<0.001)$ and no significant interaction between time and group $(P=0.422)$ are shown. $B A$ : before administration of DMT, A: immediately after administration of DMT, A10, A20, A30: 10, 20 and 30 minutes after administration of DMT, EA: end of anesthesia. 
There were significant decreases in both MAP and HR over time after DMT administration. However, there was no significance difference between the two groups (Figs. 3, 4).

\section{DISCUSSION}

In this study, we found that there was no difference in the time to reach RSS-3 sedation in elderly patients even with slower administration of the same loading dose of DMT. These results suggest that different administration duration of the same loading dose may produce similar sedative effects in elderly patients.

At an effective concentration of $0.5-1.25 \mathrm{ng} / \mathrm{ml}$ (plasma concentration $0.7-1.9 \mathrm{ng} / \mathrm{ml}$ ), DMT allows memory preservation, as well as analgesic and sedative effects [8]. In clinical anesthesia, DMT is mostly used to administer a loading dose over a 10 minutes. One might predict that the time to sedation would be prolonged when the loading dose is slowly administered. We predicted differences in the time required to induce RSS-3 sedation due to the higher dose during a 15 minute administration period in group $\mathrm{C}$; however, there was no time difference between the two groups despite the difference in administered dose $(23.3 \mu \mathrm{g}$ in group $\mathrm{S}$ vs. $32.5 \mu \mathrm{g}$ in group C). In this study, we only used the RSS tool to evaluate

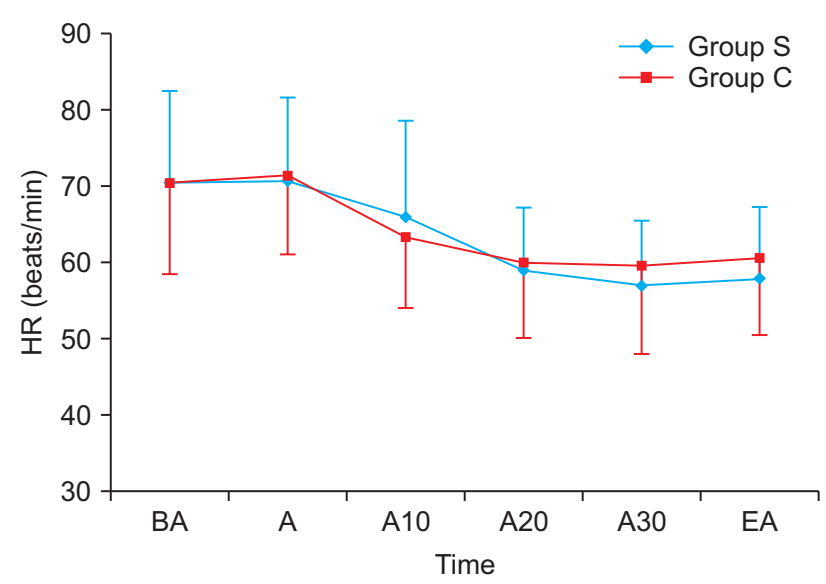

Fig. 4. Changes in heart rate (HR). Graph shows the mean values and standard deviations. Group S: a loading dose of dexmedetomidine (DMT) of $0.5 \mu \mathrm{g} / \mathrm{kg}$ over 20 minutes, followed by a continuous infusion of $0.4 \mu \mathrm{g} / \mathrm{kg} / \mathrm{h}$. Group C: a loading dose of DMT of $0.5 \mu \mathrm{g} / \mathrm{kg}$ over 10 minutes, followed by a continuous infusion of $0.4 \mu \mathrm{g} / \mathrm{kg} / \mathrm{h}$. A significant effect of time $(P<0.001)$ and no significant interaction between time and group $(P=0.247)$ are shown. $B A$ : before administration of DMT, A: immediately after administration of DMT, A10, A20, A30: 10, 20 and 30 minutes after administration of DMT, EA: end of anesthesia. sedation status, the level of sedation at which patients do not respond to light vocal stimulation, which could be considered to be a proper level of sedation in regional anesthesia and also an easy way to determine the patient's sedation status $[16,17]$. We believe that knowing the time required to reach RSS-3 according to the administration duration of the loading dose when using DMT in elderly patients will be useful information for anesthesiologists by suggesting various administration methods of DMT.

There were no significant differences between the two groups with regard to incidence of desaturation $\left(\mathrm{SpO}_{2}<90 \%\right)$ after DMT administration. In a previous study of elderly patients, desaturation did not occur when DMT loading doses of $0.5 \mu \mathrm{g} / \mathrm{kg}$ and $1.0 \mu \mathrm{g} / \mathrm{kg}$ were administrated over $10 \mathrm{~min}$ utes [11]. Another study found that a loading dose of $1.0 \mu \mathrm{g} /$ kg over 5 minutes resulted in 2 cases of desaturation below $90 \%$ oxygen saturation among 26 patients [18]. However, the present study noted desaturation in 6 of 58 patients (group S: 2/29, group C: 4/29), which was a slightly higher incidence than previously reported. This difference might be due to differences in airway-related conditions that affect patient airway maintenance after spinal anesthesia, including pillows used in the present and previous studies. In this study, most desaturation occurred after the loading dose was completely administered. All patients recovered spontaneous ventilation after lateral rotation of the head during desaturation. None of the patients required oxygen therapy. Therefore, the temporary desaturation in this study is thought to be due to airway obstruction, similar to a previous report [19]. However, desaturation occurs in a similar manner even when the loading dose is administered at a relatively slower rate. This could be an important clinical consideration, particularly in the elderly patients, who can be more vulnerable to hypoxic ventilatory response than younger patients [20]. Therefore, even in cases of transient desaturation, the importance of routine monitoring of patients, including initial respiratory pattern, end-tidal $\mathrm{CO}_{2}$ and pulse oximetry, should be emphasized for safe DMT use in elderly patients.

DMT exhibits a biphasic blood pressure response that is proportional to the dose. Therefore, hypo- and hypertension are possible. The incidence of complications can vary depending on administration duration, rate and patient's condition $[8,21,22]$. The risk of these complications is a major concern for clinicians when using DMT in elderly patients. In 
this study, we used the recommended dose $(0.5 \mu \mathrm{g} / \mathrm{kg})$ with different administration duration (10 vs. 20 minutes) and found no differences between the two groups with regard to the incidence of hypotension or bradycardia. There was also no biphasic response pattern. These findings are thought to be due to the finding that the initial dose difference between the two groups was not enough to induce differences in the hemodynamic responses. However, in both groups, MAP and HR consistently decreased after DMT administration through the end of anesthesia, regardless of administration duration. When referring to this study and previous study showing that hypotension and bradycardia were more frequent in elderly patients with continuous administration than in the younger patients, anesthesiologists should consider the possibility of these complications in elderly patients when continuous DMT administration is prolonged in the operating room [10].

One of the limitations of this study, as previously mentioned, is that the RSS scale alone was used to assess sedation status. Therefore, it is difficult to assess the specific qualitative difference in sedation status between the two groups. If additional sedation scale tools were used, including the bispectral index scale (BIS), we might have detected differences in the quality of sedation between the two groups [23]. However, we do not typically use the BIS in assessment of sedation while using DMT. Therefore, we did not include the BIS for sedation evaluation in our research design process.

Another limitation of this study is that we did not evaluate sedation when administrating loading doses were greater than $0.5 \mu \mathrm{g} / \mathrm{kg}$ or when it was administered less than $10 \mathrm{~min}-$ utes. These administration methods might affect the onset time and level of sedation in elderly patients. However, due to the risk of side effects, we did not use doses above the recommended dose or durations shorter than are recommended in this study.

In conclusion, the relatively slow administration of the same loading dose of DMT over 20 minutes (compared to over 10 minutes) did not prolong the time to reach RSS-3 sedation in elderly patients. Therefore, even with different administration durations, similar sedation statuses can be achieved when using the same loading dose in elderly patients.

\section{REFERENCES}

1. Hall JE, Uhrich TD, Barney JA, Arain SR, Ebert TJ. Sedative, amnestic, and analgesic properties of small-dose dexmedetomidine infusions. Anesth Analg 2000; 90: 699-705.

2. Gertler R, Brown HC, Mitchell DH, Silvius EN. Dexmedetomidine: a novel sedative-analgesic agent. Proc (Bayl Univ Med Cent) 2001; 14: 13-21.

3. Gurbet A, Basagan-Mogol E, Turker G, Ugun F, Kaya FN, Ozcan B. Intraoperative infusion of dexmedetomidine reduces perioperative analgesic requirements. Can J Anaesth 2006; 53: 646-52.

4. Carollo DS, Nossaman BD, Ramadhyani U. Dexmedetomidine: a review of clinical applications. Curr Opin Anaesthesiol 2008; 21: 457-61.

5. Fan TW, Ti LK, Islam I. Comparison of dexmedetomidine and midazolam for conscious sedation in dental surgery monitored by bispectral index. Br J Oral Maxillofac Surg 2013; 51: 428-33.

6. Paris A, Tonner PH. Dexmedetomidine in anaesthesia. Curr Opin Anaesthesiol 2005; 18: 412-8.

7. Giovannitti JA Jr, Thoms SM, Crawford JJ. Alpha-2 adrenergic receptor agonists: a review of current clinical applications. Anesth Prog 2015; 62: 31-9.

8. Ebert TJ, Hall JE, Barney JA, Uhrich TD, Colinco MD. The effects of increasing plasma concentrations of dexmedetomidine in humans. Anesthesiology 2000; 93: 382-94.

9. Tanskanen PE, Kyttä JV, Randell TT, Aantaa RE. Dexmedetomidine as an anaesthetic adjuvant in patients undergoing intracranial tumour surgery: a double-blind, randomized and placebocontrolled study. Br J Anaesth 2006; 97: 658-65.

10. Ice CJ, Personett HA, Frazee EN, Dierkhising RA, Kashyap R, Oeckler RA. Risk factors for dexmedetomidine-associated hemodynamic instability in noncardiac intensive care unit patients. Anesth Analg 2016; 122: 462-9.

11. Park SH, Shin YD, Yu HJ, Bae JH, Yim KH. Comparison of two dosing schedules of intravenous dexmedetomidine in elderly patients during spinal anesthesia. Korean J Anesthesiol 2014; 66: 371-6.

12. Ko KH, Jun IJ, Lee S, Lim Y, Yoo B, Kim KM. Effective dose of dexmedetomidine to induce adequate sedation in elderly patients under spinal anesthesia. Korean J Anesthesiol 2015; 68: 575-80.

13. Ramsay MA, Savege TM, Simpson BR, Goodwin R. Controlled sedation with alphaxalone-alphadolone. Br Med J 1974; 2: 656-9.

14. Iirola T, Ihmsen H, Laitio R, Kentala E, Aantaa R, Kurvinen JP, et al. Population pharmacokinetics of dexmedetomidine during long-term sedation in intensive care patients. Br J Anaesth 2012; 108: $460-8$

15. Angst MS, Ramaswamy B, Davies MF, Maze M. Comparative an- 
algesic and mental effects of increasing plasma concentrations of dexmedetomidine and alfentanil in humans. Anesthesiology 2004; 101: 744-52.

16. Goodwin H, Lewin JJ, Mirski MA. 'Cooperative sedation': optimizing comfort while maximizing systemic and neurological function. Crit Care 2012; 16: 217.

17. Ostermann ME, Keenan SP, Seiferling RA, Sibbald WJ. Sedation in the intensive care unit: a systematic review. JAMA 2000; 283: 1451-9.

18. Hong JY, Kim WO, Yoon Y, Choi Y, Kim SH, Kil HK. Effects of intravenous dexmedetomidine on low-dose bupivacaine spinal anaesthesia in elderly patients. Acta Anaesthesiol Scand 2012; 56: 382-7.

19. Belleville JP, Ward DS, Bloor BC, Maze M. Effects of intravenous dexmedetomidine in humans. I. Sedation, ventilation, and metabolic rate. Anesthesiology 1992; 77: 1125-33.

20. Kronenberg RS, Drage CW. Attenuation of the ventilatory and heart rate responses to hypoxia and hypercapnia with aging in normal men. J Clin Invest 1973; 52: 1812-9.

21. Bloor BC, Ward DS, Belleville JP, Maze M. Effects of intravenous dexmedetomidine in humans. II. Hemodynamic changes. Anesthesiology 1992; 77: 1134-42.

22. Gerlach AT, Blais DM, Jones GM, Burcham PK, Stawicki SP, Cook $\mathrm{CH}$, et al. Predictors of dexmedetomidine-associated hypotension in critically ill patients. Int J Crit Illn Inj Sci 2016; 6: 109-14.

23. Höhener D, Blumenthal S, Borgeat A. Sedation and regional anaesthesia in the adult patient. Br J Anaesth 2008; 100: 8-16. 